\title{
Jenseits von TARMED - Krimis aus Schweizer Arztstuben
}

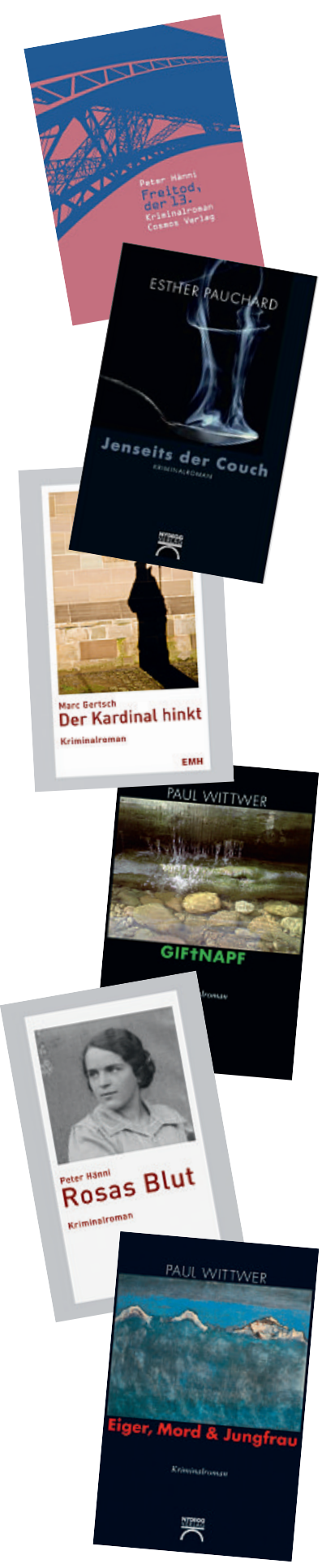

* Die Literaturangaben finden sich im Internet unter www.saez.ch $\rightarrow$ Aktuelle Nummer oder $\rightarrow$ Archiv $\rightarrow 2011 \rightarrow 8$.
Legt man grosszügige Massstäbe an, begann die Tradition des «Berner Ärztekrimis» schon im ausgehenden 19. Jahrhundert. Sherlock Holmes, Übervater aller literarischen Detektivfiguren, verschwand in den 90ern in erbittertem Kampf mit seinem teuflischen Widersacher James Moriarty in der Gischt der Reichenbachfälle im Berner Oberland. Nach massiven Leserprotesten liess ihn sein Schöpfer einige Jahre später wiederauferstehen - die Reichenbachfälle blieben untrennbar mit dem Mythos des Meisterdetektivs verbunden.

Sir Arthur Conan Doyle, der Erfinder von Sherlock Holmes, konnte erst ab 1890 von der Schriftstellerei leben. Zuvor führte er während acht Jahren bei Portsmouth eine Arztpraxis. Auch wenn man sich nicht gerade zur Behauptung versteigen will, sein Geist müsse zu den Reichenbachfällen zurückgekehrt sein und von dort aus Ärztekollegen im weiteren Umkreis inspiriert haben, ist die Häufung von Ärztekrimis, die hierzulande in den letzten Jahren erschienen sind, auf- und augenfällig. Dass die krimischreibende Ärztin und ihre drei männlichen Kollegen aus dem Kanton Bern stammen, kann angesichts der grossen Berner Tradition im Genre des Kriminalromans nicht überraschen: Wachtmeister Studer und Kommissar Bärlach, zwei Ermittler, die es zu literarischem Weltruhm gebracht haben, lösten ihre Fälle von der Bärenstadt aus.

Die neue Berner Erfolgsgeschichte beginnt am helllichten Tag, mit einer Wasserleiche an der Côte d'Azur, die das Leben des Dr. med. Franco Weber auf den Kopf stellt und den stellvertretenden Oberarzt an der Klinik für Herz-, Gefäss- und Transplantationschirurgie des Berner Inselspitals zum Detektiv wider Willen werden lässt. Mit seinem Erstling «Eiger, Mord und Jungfrau» feierte der Emmentaler Allgemeinpraktiker Paul Wittwer 2004 einen durchschlagenden Erfolg, schaffte es bis auf Rang 3 in der Schweizer Belletristik-Hitparade und hielt sich 26 Wochen in den Top Ten. Vier Jahre später doppelte er - wiederum sehr erfolgreich mit «Giftnapf» nach. Im Zentrum steht diesmal der Jungarzt Ben Sutter, ein Lebenskünstler mit blondem Pferdeschwanz und Dreitagebart. Nach dem überraschenden Tod des Dorfarztes von Trub übernimmt er interimistisch dessen Nachfolge in der Napfregion und gerät in ein Labyrinth aus Mord und dunklen Machenschaften, in dem er sich zu verlieren droht.

Im gleichen Jahr, 2008, debütierte Peter Hänni, auch er ein Berner, der als HNO-Spezialist in Solothurn praktiziert. Mit «Rosas Blut» legte er eine raffiniert konstruierte Familiensaga vor. Sein «Held» heisst Luca Clemente, ist wie sein Kollege Franco Weber in Bern chirurgisch tätig, hat aber italienische
Wurzeln, was in seinem Fall - im doppelten Sinn eine entscheidende Rolle spielt. Auch Hänni ist mittlerweile Wiederholungstäter: 2009 erschien «Samenspende», eine auf mehreren Erzählebenen angelegte, für ihren raffinierten Plot und die erzählerische Thematisierung schwieriger ethischer Fragen von der Kritik gelobte Giftmord-Geschichte.

Dass Berner Ärzte schriftstellerisch nicht an die Heimat gebunden sind, stellte im vergangenen Jahr Marc Gertsch unter Beweis. Der emeritierte Professor für Kardiologie, der als Fachbuchautor (u. a. «Das EKG - auf einen Blick und im Detail») bereits einen klingenden Namen hatte, erweiterte sein Portfolio in überzeugender Manier um einen Kriminalroman. «Der Kardinal hinkt» nicht in Bern, sondern in Mailand, Italien, und Questore Angelo Marconi - für einmal kein Arzt, sondern ein klassischer Ermittler muss sein ganzes Können aufbieten, um die komplexe Mafiageschichte zu lösen, deren Fäden bis in den Vatikan führen.

Seit kurzem wird die bisherige Männerdomäne des Schweizer Ärztekrimis in erfrischender Weise durch eine Frau aufgemischt: Esther Pauchard, Fachärztin für Psychiatrie und Psychotherapie in Burgdorf, hat sich dazu entschlossen, auch «Jenseits der Couch» zu agieren - für Krimi-Liebhaber eine gute Entscheidung. Ihre Kassandra «Ka» Bergen macht der müden Männerwelt Beine und dem (männlichen) Bösewicht die Hölle heiss ... (siehe die Rezension ihres Buchs auf Seite 297 dieser Ausgabe).

Dass Schweizer Ärztekrimis in den letzten Jahren wie Pilze aus dem Boden schiessen, mag Zufall sein zufällig ist das Phänomen krimischreibender Ärzte dagegen kaum. Die Autoren Wittwer, Hänni und Gertsch sehen im Gespräch [1, 2]* Parallelen ihrer Arbeitsweise im angestammten Beruf zur Methodik eines Detektivs. Esther Pauchard wundert sich sogar eher darüber, «dass nicht alle Ärzte schreiben, zumindest die Psychiater» [3]. Eine natürliche Affinität also, die bei entsprechendem literarischem Talent Früchte trägt - im besten Fall solche, die einem gleichzeitig das Herz wärmen und kalte Schauer über den Rücken jagen.

Wie dem auch sei: Die Schweizer Epigonen von Sir Arthur Conan Doyle und ihre Kollegin haben weitere literarische Pfeile im Köcher - von Esther Pauchard liegt ein zweites abgeschlossenes Manuskript vor, und Peter Hännis drittes Werk «Freitod, der 13.» wird Anfang März in den Buchhandel kommen. Erfreuliche Perspektiven also für Freundinnen und Freunde des gepflegten Kriminalromans ...

Bruno Kesseli 


\section{Literatur}

1 Kesseli B. Zwischen Achterbahn und Spiegellabyrinth. Schweiz Ärztezeitung. 2009;90(38):1481-4.

2 Lüthi D. Von Kardinalem und Kardialem. Schweiz Ärztezeitung. 2010;91(50):2016-8.

3 Kammermann M. Die dunklen Ansichten einer Psychiaterin. Berner Zeitung vom 28.10.2010; www.bernerzeitung.ch/region/emmental/ Die-dunklen-Ansichten-einer-Psychiaterin/ story/29984090 